\title{
Erratum Notice of Author Sequence Change Spousal concordance of diabetes mellitus among women in Ajman, United Arab Emirates
}

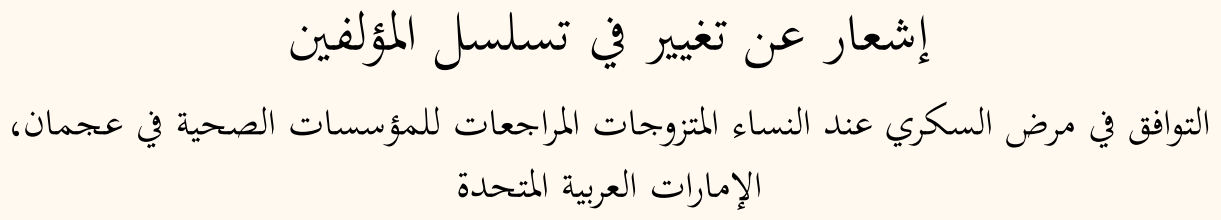

NOTICE OF ERRATUM FOR: AL-SHARBATTI ET AL. SPOUSAL CONCORDANCE OF DIABETES MELLITUS AMONG WOMEN IN AJMAN, UNITED ARAB EMIRATES. SULTAN QABOOS UNIV MED J 2016; 16:E197-202. DOI: 10.18295/SQUMJ.2016.16.02.010.

The Editors of Sultan Qaboos University Medical Journal (SQUMI) have been informed that the authors of an article by Al-Sharbatti et al. in the May 2016 issue of SQUMJ wish to change the sequence of authors in the above article. ${ }^{1}$

The first/corresponding author, Shatha S. Al-Sharbatti, contacted SQUMJ in May 2016 requesting a change in the author sequence. Al-Sharbati informed the Editors of SQUMJ that the second author, Yasmeen I. Abed, should instead be designated as the first author. However, this correction could not made as the article had already been published several days previously. For the reasons stated herein, the Editors of SQUMJ wish to notify readers that the sequence of authors for the above article is changed to the following: Yasmeen I. Abed, Shatha S. Al-Sharbatti, Lujain M. Al-Heety, Shaikh A. Basha. ${ }^{2}$

The corresponding author, Al-Sharbati, takes sole responsibility for this notice and would like to apologise to the readers, reviewers and editors of $S Q U M J$ for this correction made after publication.

\section{References}

1. Al-Sharbatti SS, Abed YI, Al-Heety LM, Basha SA. Spousal concordance of diabetes mellitus among women in Ajman, United Arab Emirates. Sultan Qaboos Univ Med J 2016; 16:e197-202. doi: 10.18295/squmj.2016.16.02.010.

2. Abed YI, Al-Sharbatti SS, Al-Heety LM, Basha SA. Spousal concordance of diabetes mellitus among women in Ajman, United Arab Emirates. Sultan Qaboos Univ Med J 2016; 16:e197-202. doi: 10.18295/squmj.2016.16.02.010. 